\title{
Osteopenia of prematurity: Assessment of Biochemical parameters in Very low birth weight preterm neonates
}

\author{
Mishra $\mathbf{S}^{1}$, Biswal $\mathbf{S}^{2}$, Parida $\mathbf{P}^{3}$ \\ ${ }^{1}$ Dr Sanjukta Mishra, Associate Professor, Department of Biochemistry, ${ }^{2}$ Dr Sebaranjan Biswal, Associate Professor, \\ Department of Paediatrics, ${ }^{3}$ Dr Preetinanda Parida, Senior Resident, Dept of Biochemistry. All are affiliated with Kalinga \\ Institute of Medical Sciences, Bhubaneswar, Odisha, India
}

Address for correspondence: Dr Sanjukta Mishra, Email: dr.sanjuktamisra@gmail.com

\begin{abstract}
Background: Osteopenia of prematurity, commonly called as metabolic bone disease (MBD), is mostly described in preterm babies (<36weeks) with very low birth weight (VLBW). This condition is characterized by a reduction in bone mineral content (osteopenia), with or without rachitic changes, and is caused by several nutritional and biomechanical factors. Objective: To determine the incidence of osteopenia of prematurity among high risk preterm VLBW babies and also to document changes in biochemical parameters including serum calcium, serum phosphate, serum alkaline phosphate (ALP) and serum creatinine in the above cases. Material and method: This prospective observational study includes all the very low birth weight babies born fromNovember 2012 to July 2014. Present study comprised of 60 VLBW neonates of which 10 were $<28$ weeks, 32 were 28-31week and 18 were 31-34weeks of gestation. Estimations of biochemical parameters were done at $2^{\text {nd }}$ week of birth and again at $6^{\text {th }}$ week to detect the incidence of osteopenia. Result: There was a significant decrease inserum calcium and serum phosphorous level where asserum ALP documented a significant increase in preterm neonates when compared to control. 14 of 60 VLBW babies developed osteopenia of prematurity at $6^{\text {th }}$ week of life. Conclusion: As observed in the present study, gestational age, birth weight and ALP are considered to be significant risk factors and are associated with osteopenia. So early detection of this condition by monitoring of biochemical parameters in high-risk cases minimizes the development of osteopeniaand prevent future complications of osteopenia.
\end{abstract}

Keywords: Osteopenia, Very low birth weight, Alkaline phosphate, Metabolic bone disease.

\section{Introduction}

Osteopenia, commonly known as metabolic bone disease (MBD), can be due to decreased bone mineralization or increased bone resorption [1]. Babies born prematurely $(<37$ th weeks of gestation or even $<28$ th week of gestation), with very low birth weight (VLBW, <1500grams) and extremely low birth weight (ELBW, <1000grams) are at increased risk of developing the condition, called as osteopenia of prematurity [2]. This condition has drawn interest of many neonatologistsbecause of its increasing incidence over last few decades. Moreover there has been growing interest in the optimal utilization of various investigations for the assessment of an infant with suspected metabolic bone disease [3]. Accumulating

Manuscript received: $04^{\text {th }}$ Feb 2016

Reviewed: $15^{\text {st }} \mathrm{Feb} 2016$

Author Corrected; 27th Feb 2016

Accepted for Publication: 08 ${ }^{\text {th }}$ March 2016 inversely associated with gestational age and body weight $[1,4,5,6]$. Most commonly, osteopenia occurs as a result of reduced transplacental mineral delivery in preterm, poor nutritional intake and excessive mineral loss after birth [2,4]. The etiology of MBD is multifactorial which includes degree of prematurity, low birth weight, exposure to medications that can alter mineral levels, immobilization, lack of mechanical stimulation, long term parenteral nutrition, delayed establishment of full feedand inadequate nutrients intake.[2,6,7]. This condition can remain silent or can lead to serious complications, which makes the preterm newborn more susceptible to rachitic changes and/or fracturesduring minimal invasive procedures and even with routine handling in neonatal intensive care units [8]. Several biochemical markers like calcium (Ca), phosphate (PO4), alkaline phosphatase [ALP] and osteocalcin, have been used for measurement of bone mineral densityin preterm infants to detect development 
of osteopenian [3]. ALP, the sum of bone, liver and intestinal isoform, with the bone isoform contributing about $90 \%$, represent a marker of bone mineralization and turnover.There are limitations to the use of total ALP as several studies observed conflicting results $[9,10]$. According to evidences, rachitic changes are more commonly associated with greater ALP levels $(>800 \mathrm{IU} / \mathrm{L})$ but can also be seen at lower levels $(600 \mathrm{IU} / \mathrm{L})[11,12]$. Radiological diagnosis is likely to be imprecise because the assessment is subjective and a major loss of bone mineral content might have to occur before characteristics changes would be apparent $[13,14]$. Increased understanding of the pathophysiology of neonatal osteopenia has raised awareness of the need for early monitoring, prevention and treatment of the condition in high-risk neonates. Given the lack of consensus on screening, it has been recommended to weekly measure serum calcium, phosphorus and ALP for early detection of osteopenia in high-risk neonates [15]. To the best of our knowledge, there is paucity of data regarding incidence of osteopenia and status of biochemical profile in premature VLBW babies, despite being a common disease in India.With this above consideration, thepresent study is undertaken to document the incidence of osteopenia in premature VLBW neonates and to evaluate the serum biochemical markers of osteopenia so as to detect such cases at an earliest, which can reduce the prevalence and severity of the condition in preterm neonates.

\section{Materials and Methods}

The prospective observational study was conducted in department of Biochemistry, Kalinga Institute of Medical Science, Bhubaneswar, in collaboration with neonatal intensive care unit (NICU), after being approved by ethical committee of the institute. All the very low birth weight (VLBW) neonates born in our hospital from November 2012 to July 2014 were enrolled in the study for evaluation. Following exclusion criteria were kept in consideration: babies diagnosed having inborn error of metabolism and babies with multiple congenital anomalies. A total of 1020 newborn were evaluated, out of that 482 babies were admitted to NICU. 92 babies were identified as premature $(<34$ week) born. As per exclusion criteria cited above, total 32 babies, out of 92 premature babies, were not included in our study. Moreover few babies, who could not be followed up, were also excluded. Finally a total number of $60 \mathrm{VLBW}$ babies were enrolled for the present study. A comparative data analysis was proposed with at least 20 number of control (VLBW term neonates admitted to NICU for hyperbilirubinemia). Written informed consent was taken from all parents of both VLBW neonate study participants and healthy control. Babies were constantly under observation and were followed up both clinically and biochemically for detection of osteopenia of prematurity. Anthropological parameters like weight, height, gestational age, mode of delivery, cause of premature birth, head circumference, were noted down. The demographic details, course in the hospital and nutritional supplementation were recorded as per performa prepared by us. Blood samples were collected from both the study participants for ascertaining the followings biochemical parameters: serum alkaline phosphatase (ALP), serum calcium (Ca), serum phosphate (PO4), and serum creatinine. All the investigations were taken up from 2 nd week of chronological age and were repeated at 6 th week. During follow up, number of babies developing osteopenia was observed and in incidence was computed. Blood samples were analyzed using Cobas-400 fully automated analyzer.

Statistical analysis of this study was performed by Microsoft excel and SPSS 16. Obtained values were expressed as mean \pm SD.ANOVA analysis, student t-test and post hoc analysis were adopted to observe the percentage of outcome variables and to find the correlation of changes. A p value $<0.005$ is considered as statistically significant.

Table 1: Biochemical Parameters at 2 weeks of age

\begin{tabular}{|l|l|l|l|l|l|}
\hline Parameter & $<\mathbf{2 8}$ weeks & $\mathbf{2 8 - 3 0}$ weeks & $\mathbf{3 1 - 3 4}$ weeks & Term & p value \\
\hline $\begin{array}{l}\text { Serum Ca } \\
(\mathrm{mg} / \mathrm{dl})\end{array}$ & $8.82 \pm 1.027$ & $8.68 \pm 1.53$ & $8.62 \pm 0.635$ & $9.49 \pm 0.457$ & 0.067 \\
\hline $\begin{array}{l}\text { Serum PO4 } \\
(\mathrm{mg} / \mathrm{dl})\end{array}$ & $3.2 \pm 0.679$ & $4.46 \pm 0.763$ & $4.85 \pm 0.615$ & $5.58 \pm 0.477$ & 0.0001 \\
\hline $\begin{array}{l}\text { Serum ALP } \\
(\mathrm{IU} / \mathrm{L})\end{array}$ & $678.6 \pm 161.78$ & $585 \pm 131.26$ & $524.35 \pm 104.98$ & $311.75 \pm 26.34$ & 0.0001 \\
\hline $\begin{array}{l}\text { Serum } \\
\text { Creatinine } \\
(\mathrm{mmol} / \mathrm{L})\end{array}$ & $0.605 \pm 0.146$ & $0.541 \pm 0.09$ & $0.5 \pm 0.075$ & $0.36 \pm 0.06$ & 0.0001 \\
\hline
\end{tabular}


Table 2: Biochemical parameters at 6weeks of age

\begin{tabular}{|l|l|l|l|l|}
\hline Parameter & $<\mathbf{2 8 W e e k s}$ & $\mathbf{2 8 - 3 0 w e e k s}$ & $\mathbf{3 1 - 3 4 w e e k s}$ & p value \\
\hline $\begin{array}{l}\text { Serum Ca } \\
(\mathrm{mg} / \mathrm{dl})\end{array}$ & $9.17 \pm 0.39$ & $9.24 \pm 0.35$ & $9.98 \pm 0.38$ & 0.23 \\
\hline $\begin{array}{l}\text { Serum PO4 } \\
(\mathrm{mg} / \mathrm{dl})\end{array}$ & $3.2 \pm 0.12$ & $4.1 \pm 0.25$ & $4.8 \pm 0.27$ & 0.009 \\
\hline $\begin{array}{l}\text { Serum ALP } \\
(\mathrm{IU} / \mathrm{L})\end{array}$ & $947 \pm 121.6$ & $602 \pm 105.2$ & $518 \pm 113$ & 0.009 \\
\hline
\end{tabular}

Table 3: Incidence of osteopenia based on birth weight

\begin{tabular}{|l|l|l|l|l|}
\hline & $\begin{array}{l}\text { Weight } \\
<1000 \mathrm{gms}\end{array}$ & $\begin{array}{l}\text { Weight 1000- } \\
1200 \mathrm{gms}\end{array}$ & $\begin{array}{l}\text { Weight 1200-1500 } \\
\text { gms }\end{array}$ & $\begin{array}{l}\text { Total number of } \\
\text { cases }\end{array}$ \\
\hline $\begin{array}{l}\text { No. of Babies in the } \\
\text { study group }\end{array}$ & $21(35 \%)$ & $21(35 \%)$ & $18(30 \%)$ & 60 \\
\hline $\begin{array}{l}\text { No. of babies with } \\
\text { osteopenia } \\
\text { prematurity }\end{array}$ & $11(52 \%)$ & $3(14.28 \%)$ & 0 & $14(23.33 \%)$ \\
\hline
\end{tabular}

Table 4: Incidence of osteopenia based on gestational age

\begin{tabular}{|l|l|l|l|l|}
\hline & $<28$ weeks & $28-31$ weeks & $31-34$ weeks & Total no. of cases \\
\hline $\begin{array}{l}\text { No. of babies in } \\
\text { study group }\end{array}$ & $10(16.67 \%)$ & $32(53.33 \%)$ & $18(30 \%)$ & 60 \\
\hline $\begin{array}{l}\text { No. of babies in } \\
\text { osteopenia } \\
\text { prematurity }\end{array}$ & $6(60 \%)$ & $6(18.75 \%)$ & $2(11.11 \%)$ & $14(23.33 \%)$ \\
\hline
\end{tabular}

\section{Observation}

Present study comprised of 60 preterm VLBW babies, out of which 39 were male child and 21 were female child. As per the recorded observations, there were 10 neonates $(16 \%)$ less than 28 weeks, 32 neonates $(53.3 \%)$ within 28-32 weeks, and 18(30\%) were within 31-34 weeks. In the present study, the distribution ofbabies (both cases and control) based on birth weight was like this: 28 neonates were $<1000$ grams $(35 \%)$, 28 belonged to birth weight 1000-1200grams (35\%), 18 neonates belonged to $1200-1500 \operatorname{grams}(22.5 \%)$ and 6 babies were $>1500$ grams $(7.5 \%)$. The mean values of serum biochemical parameters at 2 weeks of age are documented in Table-1, which reveals the following data: serum $\mathrm{Ca}$ and $\mathrm{PO} 4$ levels were significantly decreased at $<28$ weeks, 28-30 weeks and 31-34 weeks as compared to term controls, but the decrease was insignificant when compared between 28-30weeks and 31-34weeks. Serum ALP levels were significantly increased at $<28$ weeks, 28-30weeks and 31-34weeks but levels did not differ significantly when compared between 28-30 weeks and 31-34 weeks. Serum creatinine increased significantly in preterm neonates as compared to term neonates. Table- 2 depicted the above parameters at 6 weeks of age. As evident from the data, there was no significant difference in serum $\mathrm{Ca}$ level, where as serum PO4 level showed a significant decrease at $<28$ weeks, in comparison to the other two groups. Serum ALP, a marker of bone turnover, was observed to be highest with $<28$ week babies, both at 2nd week and 6th week of life. But no significant difference was observed between 28-30weeks and 3134 weeks. Another relevant finding of our study is the detection of osteopenia, based on birth weight and stats of biochemical markers (Table-3). Out of 60 enrolled premature babies in our study, 14 neonates $(23.3 \%)$, developed biochemical parameters suggestive of osteopenia (cut off value of ALP taken as $\leq 800 \mathrm{IU} / \mathrm{L}$ ), out of which 11 number of babies (out of $21,52 \%$ ) were from $<1000 \mathrm{gms}$ and 3 (out of 21, 14.2\%) were from $1000-1200$ gms birth weight. There was no incidence of osteopenia observed in the category of 1200-1500gms. Table-4 revealed maximum incidence of osteopenia $(60 \%)$ from the gestational age $<28$ weeks. A total of 6 out of $32(18.7 \%)$ and only 2 out of $18(11.11 \%)$ cases were from 28-31weeks and 31-34weeks respectively. 


\section{Discussion}

Prematurity is the leading cause of neonatal mortality at $25 \%$ [16]. Preterm neonates with VLBW andELBW, are most vulnerable for osteopenia of prematurity and metabolic bone disease, secondary to insufficient transplacental mineral delivery, postnatal nutrition compromise and excessive urinary loss after birth $[1,17]$. Moreover, use of several medications for neonatal diseases like high dose systemic corticosteroid, diuretics, long-term methyl xanthine can impair bony growth and increase the risk of osteopenia $[1,2]$. Osteopenia of prematurity is reported to be $20-30 \%$ in VLBW and $60-75 \%$ in ELBW babies by several studies in this regard $[18,19]$.

Present study aimed to determine the incidence of osteopenia of prematurity and to look into any significant difference in biochemical profile. Out of 60 enrolled preterm neonates in the current study, incidence of osteopenia of prematurity was reported to be $23.3 \%$, based on birth weight. Our finding can be comparable to the finding of several other recent studies in this regard. Lee et al reported a high incidence of $44 \%$, among 55 ELBW infants [19]. Another prospective study conducted in VLBW observed the prevalence of osteopenia to be $32.7 \%$ [20]. Similarly Viswanath et al confirmed $30.9 \%$ prevalence in the radiological evidence of MBD among 230 ELBW babies [21]. One more recent study also confirmed $43.9 \%$ incidence rate of osteopenia in ELBW neonates [22]. Table-4, reflects the incidence of osteopenia based on gestational age, which documented a very high incidence of osteopenia $(60 \%)$ in preterm babies $<28$ weeks. This might be due to extreme prematurity, which leads severe insufficiency in transplacental mineral delivery [17].

Moreover incidence rate of osteopenia might be associated with several factors like postnatal nutrition status, comorbidities and type of evaluation. Similar to our findings, Bass et al described an inverse relationship between MBD and gestational age [23]. With reference to the above finding, it can be concluded that birth weight $<1500 \mathrm{gm}$, more specifically $<1000$ gms and gestational age $<28$ weeks are considered as important predictor of osteopenia, apart from other factors like total parenteral nutrition for prolonged period, use of steroid and use of diuretics $[2,24]$. According to the result of our study, serum calcium levels at 2 weeks of age (Table-1) in babies $<28$ weeks, $28-30$ weeks, $31-34$ weeks of age were $8.82 \pm 1.027 \mathrm{mg} / \mathrm{dl}$, $8.86 \pm 1.53 \mathrm{mg} / \mathrm{dl}$ and $8.62 \pm 0.63 \mathrm{mg} / \mathrm{dl}$ respectively and there was no significant difference of results in different group. Similarly no significant difference was noted in the result of serum calcium at 6th week also. However serum calcium was reported to be significantly lower in preterm neonates when compared to term controls, which is consistent with other study in this regard [25]. Hence serum calcium has no significant importance to screen high-risk cases prone to develop osteopenia. This can be explained by the fact that neonates might be able to maintain normal serum calcium at the expense of removal from bone. Further serum $\mathrm{Ca}$ might get affected by hypophosphatemia, a conditionnot related to osteopenia [26].

Another observational finding in our study population was that all VLBW neonates were supplemented with calcium $(100-120 \mathrm{mg} / \mathrm{kg} / \mathrm{day})$, phosphorous (50$70 \mathrm{mg} / \mathrm{kg} /$ day) and 400IU of Vitamin D after getting full enteral nutrition. Based on biochemical parameters of bone metabolic status, nutritional supplementations were modified individually, which may explain higher phosphate levels in our study population as compared to other studies [19]. Another relevant finding of our study is that, serum ALP levels, an indicator of high bone metabolism, were significantly increased at all gestational age compared to term neonates (Table1,2).Our study evidences suggest that ALP concentration of $\geq 800 \mathrm{IU} / \mathrm{L}$ may cause osteopenia. In this study mean level of peak ALP was higher in $<28$ week preterm group at 6 th week $(947 \pm 121.6 \mathrm{IU} / \mathrm{L})$. The rising trend of ALP in different preterm groups from 2 nd week to 6 th week, clearly suggests that biochemical tests at 6weeks of age is of more diagnostic value to detect development of osteopenia.

Similar to our finding, Mitchell et al in his cohort study concluded the association of increased ALP and higher risk of osteopenia in preterm neonates [11]. According to some data, preterm neonates having rickets register a higher ALP level compared to control $(952.2+413.8$ vs $524.7+158.2 \mathrm{IU} / \mathrm{L})$ [19]. In another study, it was described that increase ALP signifies increased bone osteoblastic activity in preterm babies [27]. Also other researchers have suggested to prevent increase ALP by supplementing the preterm with appropriate minerals [28]. Moreover, there are conflicting reports on the effect of minerals on ALP level $[9,10]$. However it can be concluded that ALP, an indicator of high bone metabolism, rises within first few weeks of birth and increases further in mineral deficiency [20]. So it can be taken as one of the significant biochemical marker for detecting osteopenia of prematurity. In our study, serum creatinine levels were significantly increased in preterm 
neonates compared to term neonates. Increased creatinine signifies lower GFR in preterm. It has been suggested that premature birth impairs final development of nephrons after birth [29]. Glomerular function shows a progression directly correlated to gestational age and postnatal age in preterm infants.

\section{Conclusion}

Prematurity is the most important risk factor for neonatal osteopenia. As described previously, there are evidences of inverse relationship of neonatal osteopenia with gestational age and birth weight. This problem is compounded by risk of pathological fracture, later on rickets. It is therefore important to detect the condition at the earliest by closely monitoring biochemical parameters in high-risk VLBW infants. So early detection, treatment and prevention of development of complications are the preferred strategies.

Limitation of the study: Our study was limited for small sample size and was limited to single center study. Since there was unavailability of DEXA scan or quantitative ultrasound in our center, we could not correlate radiological osteopenia with biochemical parameters of osteopenia of prematurity. Moreover we could not include maternal nutritional effect on neonates as in our tertiary care center, most of the mothers did not have proper antenatal check up.

\section{Funding: Nill, Conflict of Interest: None Permission of IRB: Yes}

\section{References}

1. Lam HS, So KW, Ng PC. Osteopenia in neonates: A review. HK J Paediatr(new series). 2007;12:118-124.

2. Rustico SE, Calabri AC, Garber SJ. Metabolic bone disease of prematurity.J of clin trans endocrinol. 2014;1:85-91.

3. Koo WW.Laboratory assessment of nutritional metabolic bone disease in infants.ClinBiochem. 1996 Oct;29(5):429-38.

4. Harrison CM, Gibson AT.Osteopenia in preterm infants.Arch Dis Child Fetal Neonatal Ed. 2013 May;98(3):F272-5. doi: 10.1136/archdischild-2011301025. Epub 2012 May 3.

5. Brooke OG, Lucas A.Metabolic bone disease in preterm infants.Arch Dis Child. 1985 Jul;60(7):682-5.
6. Backström MC, Kuusela AL, Mäki R.Metabolic bone disease of prematurity.Ann Med. 1996 Aug;28(4):27582.

7. Schultheis L.The mechanical control system of bone in weightless spaceflight and in aging.ExpGerontol. 1991;26(2-3):203-14.

8. Koo WW, Sherman R, Succop P, Krug-Wispe S, Tsang RC, Steichen JJ, Crawford AH, Oestreich AE.Fractures and rickets in very low birth weight infants: conservative management and outcome.J PediatrOrthop. 1989 May-Jun;9(3):326-30.

9. Lindroth M, Westgren U, Laurin S.Rickets in very low birthweight infants. Influence of supplementation with vitamin D, phosphorus and calcium.ActaPaediatr Scand. 1986 Nov;75(6):927-31.

10. Pittard WB 3rd, Geddes KM, Hulsey TC, Hollis BW.Osteocalcin, skeletal alkaline phosphatase, and bone mineral content in very low birth weight infants: a longitudinal assessment.Pediatr Res. 1992 Feb;31(2):181-5.

11. Mitchell SM, Rogers SP, Hicks PD, Hawthorne KM. High frequency of elevated alkaline phosphatase activity and rickets exist in extremely low birth weight infants despite current nutritional support. BMC Paediatr. 2009 Jul 29;9:47

12. Koo WW, Succop P, Hambidge KM.Serum alkaline phosphatase and serum zinc concentrations in preterm infants with rickets and fractures.Am J Dis Child. 1989 Nov;143(11):1342-5.

13. Mazess RB, Peppler WW, Chesney RW, Lange TA, Lindgren U, Smith E Jr.Does bone measurement on the radius indicate skeletal status? Concise communication.J Nucl Med. 1984 Mar;25(3):281-8.

14. Syed Z, Khan A.Bone densitometry: applications and limitations.J ObstetGynaecol Can. 2002 Jun;24(6):476-84.

15. Harrison CM, Johnson K, McKechnie E.Osteopenia of prematurity: a national survey and review of practice.ActaPaediatr. 2008 Apr;97(4):407-13.

16. Mathews TJ, MacDorman MF.Infant mortality statistics from

the 2003 period linked birth/infant death data set.Natl Vital Stat Rep. 2006 May 3;54(16):1-29. 
17. Salle BL, Braillon P, Glorieux FH, Brunet J, Cavero E, Meunier PJ.Lumbar bone mineral content measured by dual energy X-ray absorptiometry in newborns and infants.ActaPaediatr. 1992 Dec;81(12):953-8.

18. Sing M. Osteopenia of Prematurity In: Care of new born. $7^{\text {th }}$ Edition. India. Sagar publication. 2010:382384

19. Lee SM, Namgung R, Park MS. High incidence of rickets in extremely low birth weight infants with sever parenteral nutrition associated cholestasis and bronchopulmonary dysplasia. J Korean Med. 2012;27:1532-5

20. Arani KS, Lotfi A, Jahangir M. Metabolic bone disease in very low birth weight neonates. Iranian jneonatol. 2015;6(2):7-13

21. Viswanathan S, Khasawneh W, McNelis K, Dykstra C, Amstadt R, Super DM, Groh-Wargo $\mathrm{S}^{3}$, Kumar $\mathrm{D}^{4}$.Metabolic bone disease: a continued challenge in extremely low birth weight infants.JPEN J Parenter Enteral Nutr. 2014 Nov;38(8):982-90. doi: 10.1177/0148607113499590. Epub 2013 Aug 20.

22. Namgung R, Lee SM, Ehun HS. Metabolic bone disease of prematurity. Neonatal Med. 2013;20(3):276282.
23. Bass JK, Chan GM.Calcium nutrition and metabolism during infancy.Nutrition. 2006 Oct;22(10):1057-66. Epub 2006 Jul 10.

24. So KW,Ng PC. Treatment and prevention of neonatal osteopenia. Current Paediatr. 2005;15:106-113

25. Chauhan SS, Sarkar PD, Bhimte B.Prematurity and related biochemical outcomes: study of bone mineralization and renal function parameters in preterm infants.Biochem Res Int. 2011;2011:740370. doi: 10.1155/2011/740370. Epub 2011 Oct 18.

26. Lyon AJ, McIntosh N, Wheeler K, Brooke OG.Hypercalcaemia in extremely low birthweight infants.Arch Dis Child. 1984 Dec;59(12):1141-4.

27. Chen M, Ashmeade T, Carver JD.Bone ultrasound velocity in small- versus appropriate-for-gestational age preterm infants.J Perinatol. 2007 Aug;27(8):485-9. Epub 2007 Jun 14.

28. Lothe A, Sinn J, Stone M.Metabolic bone disease of prematurity and secondary hyperparathyroidism.J Paediatr Child Health. 2011 Aug;47(8):550-3. doi: 10.1111/j.1440-1754.2011.02019.x. Epub 2011 Mar 10.

29. Rodriguez MM, Gomez A, Abitbol C, Chandar J, Montané B, Zilleruelo G.Comparative renal histomorphometry: a case study of oligonephropathy of prematurity.PediatrNephrol. $2005 \quad$ Jul;20(7):945-9. Epub 2005 Apr 26.

\section{How to cite this article?}

Mishra S, Biswal S, Parida P. Osteopenia of prematurity: Assessment of Biochemical parameters in Very low birth weight preterm neonates: Int J Pediatr Res 2016;3(3):140-145.doi:10.17511/ijpr.2016.i03.01. 